\title{
RELEVANCE OF PHONOLOGICAL AWARENESS INTERVENTION TO A JORDANIAN EFL CLASSROOM
}

\author{
Yasser Abdullah Saleh Al Tamimi \\ Associate Professor of Linguistics \\ English Department \\ AlFaisal University \\ Alm'athar PO. Box 50927 \\ Riaydh 11533 \\ Saudi Arabia \\ yaltamimi@alfaisal.edu
}

\begin{abstract}
Building on Tamimi and Rababah (2007), the present study is an investigation of the effectiveness of explicit phonological awareness intervention in contrast with formal classroom instruction on developing phonological awareness skills for Jordanian EFL second-graders in a governmental school. Based on some views (Adams, 1990; Yopp, 1992; Stanovich, 1994; and Chard and Dickson, 1999) a phonological training program was designed with focus on five phonological awareness skills, viz., segmentation, isolation, deletion, substitution and blending, and their respective sub-skills. On measures of Robertson and Salter's (1997) Phonological Awareness Test (PAT), the experimental group that had undergone 15 40-minute phonological awareness sessions outperformed in deletion, substitution and blending skills the control group which continued to receive formal classroom instruction based on Action Pack 2. The findings corroborate previous research conclusions favoring explicit phonological awareness interventions; thus giving less credit to formal classroom instruction. The study also calls for integrating phonological awareness interventions in Jordanian basic stages' curricula.
\end{abstract}

Key words: phonological awareness, segmentation, isolation, deletion, substitution, blending, PAT test, Action Pack

\section{INTRODUCTION}

Phonological awareness (PA) as an index of emergent literacy has received much research concern. Research on this key metalinguistic concept 
provides ample evidence in favor of its relevance to early reading development (e.g. Ball and Blachman, 1991; Ehri et al., 2001; Littleton, Wood and Chera, 2006; Tamimi and Rababah, 2007). In other words, phonological deficits have been found to be a precursor to reading disabilities (e.g. Wagner and Torgeson, 1987; Wanzek et al., 2002). Thus, monolingual or EFL children with weak PA, for instance demonstrate, difficulties in analyzing words into their constituent phonemes, and hence they are regarded as disadvantaged in learning how to decode words. This, in turn, can lead to further difficulties in reading fluently and comprehension of written text (Leafstedt, Richards, and Gerber, 2004).

Such evidence amassing over the past four decades brings attention to PA as a critical phonological aptitude, and raises the point as to the more effective approach for developing it: formal classroom instruction versus PA interventions. While the traditional strategy represented by the pure-whole language approach assumes that PA is only truly naturally acquired (Foormn and Liberman, 1989), there is some growing evidence, suggesting that PA can be explicitly taught, and can yield more fruitful outcome (e.g. Snow, Burns and Griffin, 1998; Brady et al., 1994).

Evidence in favor of the new approach comes primarily from research on monolingual children (e.g. Bus and Van Ijzendoorn, 1999; Ehri et al., 2001), and secondarily, from studies on EFL students (e.g. Lundberg, Frost, and Petersen, 1988; Foorman et al., 1991). Arab EFL learners have not, to my knowledge, provided evidence (if any) in this direction. It is only in Tamimi and Rababah (2007) that one may find some initial indications against the pure-whole language approach as their main concern was studying the correlation between PA and the development of Jordanian EFL first-graders' early word-reading. Contributing to the debate stated above requires a thorough and a more focused investigation of the subject matter.

Tamimi and Rababah's findings of noticeably very low first-graders' mean scores in word-reading even after being exposed to some PA training suggest that experimenting on Jordanian EFL second-graders may reflect more transparent responses. This will still be quite acceptable in PA research as the Jordanian second-graders' age average (7.1) remains within the normal age group (5-8 years-old) eligible for such investigation (Catts et al., 2001). Besides, basing the study on second-graders gets more interesting when one considers the Jordanian English Language National Team's (2006) challenging phonological expectations by the end of the school year (see section II below).

Taking Jordanian EFL second-graders in a governmental school in Amman as subjects, the purpose of the present study is to test the hypothesis that explicit PA interventions can be more effective in building their PA skills than formal classroom instruction currently practiced in Jordanian schools, as most likely the case elsewhere. Further evidence corroborating any of these competing approaches may contribute to settling this dispute, and to providing 
insight into how this core metalinguistic ability can be more effectively developed.

\section{PRELIMINARIES}

This section introduces some general phonological problems Jordanian EFL learners normally have at both school and university levels. It also sheds some light on Jordanian EFL second-graders' curriculum and phonological challenges.

\subsection{Jordanian EFL Learners' Phonology}

Apart from their well-documented reading and writing problems (Kharma, 1981; Matter, 1990; Ryan and Meara, 1991; Rababah, 2005), Arab EFL learners generally face many phonological difficulties. Iraqi EFL learners, for instance, encounter pronunciation problems related to English consonant sounds (Aziz, 1974a); English diphthongs (Aziz, 1974b); and English word stress (Aziz, 1980). In addition, Egyptian EFL students struggle to learn the English intonational patterns (Khalil, 1987). Research on EFL learners' pronunciation mainly attributes such difficulties to phonological differences between English and Arabic (e.g. Fender, 2003), and to shortcomings in formal classroom instruction (e.g. Suter, 1976).

Jordanian EFL students are no exception as their phonetic and phonological errors are recurrent and numerous, including, mispronunciation of English consonants; vowels; and diphthongs, syllabification, lexical stress, sentence stress, and intonation. Their struggle with learning accurate English pronunciation starts from the first-grade (if not before), and continues up until the university level (if not after). Errors in assigning lexical stress (Anani, 1989), as well as in predicting sentence stress (Abd Al-Haq, 1997), for example, are routinely committed by English language majors in different Jordanian universities. According to Muqattash (1983: 169), they "continue to make some basic errors in pronunciation.... They cannot express themselves comfortably and efficiently either when dealing with "academic topics" or "common every day topics".

Overcoming such continuous problems evolving over the years of teaching English as a foreign language in this country requires a scholarly reconsideration of the current EFL teaching strategies used for building EFL children's phonology. It also requires giving much attention to the new approach, especially since it has been claimed to be more effective in developing children's PA skills in basic school stages. If this were true, adopting PA interventions in these stages might remarkably eliminate later stages' phonological problems. 


\subsection{Second-Graders' Curriculum and Phonological Challenges}

Action Pack, a twelve-level course, is used for teaching English in Jordanian state schools; from the basic to the secondary stage. Its material includes, student's book; activity book and handwriting book; audio cassettes; CD-Rom, in addition to the teacher's book. Action Pack 2 is just one array of this series designed for second-graders, presumably compatible with their language attainment and age group. It is based, as stated on the cover of the book, "on the most modern methods of teaching language, combining a topicbased approach with functional language practice, careful attention to grammar and vocabulary and a comprehensive skills syllabus". It offers students: "Modern, interesting and relevant topics, a clear and systematic approach to grammar, with thorough practice, integrated skills with a particular focus on reading and writing, consistent building and recycling of vocabulary, special sections devoted to functional and situational language, project work at the end of every module, [and] the development of critical thinking skills" (ibid)

Guidance and assessment of Action Pack 2 material were made by the Evaluation and Adaptation Committee formed by the Ministry of Education, which has decided to adopt this book for Jordanian schools in accordance with the approval of the Board of Education decision No.7, dated June 25, 2006 for the 2006-2007 academic year.

Having used Action Pack 2, the second-graders are supposed to meet by the end of the year a number of pronunciation expectations set up by the English Language National Team (2006), as stated below:

Broadly, "the general aim of speaking is to speak English clearly and correctly in the context of basic and simple guided short exchanges and presentations." (ELNT, 2006: 20). More specifically, the second-graders should be able to "pronounce two-syllable words with the correct stress, pronounce words correctly when talking about animals, clothes, presents and members of the family, ask and respond to short simple questions about clothes and colors using short sentences, sing short simple songs after listening to a tape, and repeat short simple rhymes after listening to a tape" (ibid).

As part of a pilot study, a questionnaire enquiring about the children's proficiency in these pronunciation abilities was impressionistically completed at the end of 2006-2007 school year by eight senior second-grade teachers from different state schools in Amman (including the subjects' school; see section IV below). The teachers were requested to provide an objective assessment based on the ELNT's expectations for the purpose of scientific research. The average of the teachers' assessments is presented in percentages in table (1) below. 
Table (1): Teachers' assessment of 2nd-graders' pronunciation expected by ELNT (2006)

\begin{tabular}{lllllll}
\hline $\begin{array}{l}\text { Skills } \\
\text { expected } \\
\text { from } 2^{\text {nd }} \text { - } \\
\text { graders }\end{array}$ & $\begin{array}{l}\text { Correct } \\
\text { stressing } \\
\text { of di- } \\
\text { syllabic } \\
\text { words }\end{array}$ & $\begin{array}{l}\text { Correct } \\
\text { pronunciation } \\
\text { of words }\end{array}$ & $\begin{array}{l}\text { Correct } \\
\text { asking and } \\
\text { responding }\end{array}$ & $\begin{array}{l}\text { Correct } \\
\text { singing } \\
\text { of } \\
\text { short } \\
\text { simple } \\
\text { songs }\end{array}$ & $\begin{array}{l}\text { Correct } \\
\text { repetition } \\
\text { of short } \\
\text { simple } \\
\text { rhymes }\end{array}$ & $\begin{array}{l}\text { Speaking } \\
\text { English } \\
\text { clearly } \\
\text { and } \\
\text { correctly }\end{array}$ \\
\hline $\begin{array}{l}\text { Mastery } \\
\text { Percentages }\end{array}$ & $40 \%$ & $42 \%$ & $44 \%$ & $52 \%$ & $75 \%$ & $44 \%$ \\
\hline
\end{tabular}

This assessment, though impressionistic, may be regarded as semiauthentic as it was carried out by experienced teachers whose judgment on their students' proficiency was based on their own familiarity and close observation. It may be concluded from the table that the second-graders' pronunciation is generally far below the ELNT's expectations, and that the formal classroom instruction they had already received throughout the year was not much helpful in developing the required phonological abilities. Explicit PA interventions might put the children in a better position to meet such challenges.

\section{REVIEW OF RELATED LITERATURE}

As stated earlier, a great number of studies conducted in a number of countries around the world, most often with 5-to-8-year-old children as subjects, have primarily focused on PA correlation with early reading development (e.g. Lundberg, Frost, and Petersen, 1988; Cunningham, 1990; Adams and Henry, 1997; Gillet, Temple and Crawford, 2004; Anthony and Francis, 2005; Tamimi and Rababah, 2007). Not only have these studies revealed the relevance of PA to early reading progress, but also they have raised the debate as to the most effective strategy for building this fundamental metalinguistic ability.

Advocates of the pure whole-language approach, on one hand, contend that PA is only truly naturally acquired (Foorman and Liberman, 1989); children spontaneously develop auditory-oral metalinguistic proficiency, including PA, as a component of normal language development. This approach typically takes the form of formal classroom instruction, and it has been so pervasive in kindergartens and schools around the globe since time immemorial. Proponents of PA interventions, on the other hand, simply believe that PA can be explicitly taught and it can be more effective in developing PA for kindergartners and school children, as evidenced below.

Monolingual children have been most often the main research concern. Experiments on them provide ample evidence in favor of explicit PA interventions. Across five studies, for instance, Torgesen, (2000) finds that 
92-98 percent of young monolingual children responded to PA training, and thereby reduced their risk of developing word-reading difficulties. In two meta-analyses, Bus and Van Ijzendoorn, (1999) and Ehri et al., (2001) review research on PA intervention, and provide evidence for its efficiency in building monolingual children's PA. Moreover, based on 52 empirical studies, The National Reading Panel's 2000 report to the US Congress describes PA remediation as "beneficial for typically developing children, for young children at risk, for reading difficulties, and for poor readers." (Anthony and Francis, 2005: 255).

Research has also given attention to EFL students' PA development, as according to Snow, Burns, and Griffin (1998), for EFL as well as for monolingual students, explicit PA instruction might be an effective strategy. In the same vein, Layton et al. (1998: 38) states, "the effects of weak or under-developed awareness can be reduced by intensive training, particularly that which promotes knowledge and use of the links between letters and the individual sounds they represent."

This view has been confirmed by a number of studies on bilingual children. Lundberg, Frost, and Petersen (1988), for example, subject 235 Danish kindergartners to an eight-month PA training program, compare their awareness with that of a control group comprising 155, and conclude that with explicit instruction, PA can be developed before, and independently of, alphabetic instruction. Lundberg, Olofsson, and Wall's (1980) study on Scandinavian EFL kindergartners yield similar results. Moreover, Foorman et al.'s (1991) investigation on six first-grade EFL classrooms reveals superiority in phonologically trained classes (for further evidence, see Stuart, 1995; Vaughn et al., 2001; and Wood , 2005).

Acknowledging the effectiveness of PA instruction, Chera (2000) developed a "talking- books"- software based on the 'Bangers and Mash' reading scheme (published by Longman) with the purpose of promoting PA in children in the initial stages of learning to read. Subsequent evaluation of this innovation indicates that even a short interaction with the software has the potential to enhance PA in children (Chera and Wood, 2003; Littleton, Wood and Chera, 2006). However, "despite the evidence, activities to build phonological awareness have not routinely been integrated into our kindergarten and first grade classrooms" (Blachman, 1991: 53). Possibly, more evidence in the same direction is still needed in order to create the urge for this integration.

Given the paucity of research on Arab EFL children, the present study examines the effectiveness of PA interventions for Jordanian EFL secondgraders (not first-graders for the reasons discussed in section I) in a governmental school in Amman. In addition to contributing to the debate stated above, the findings of this research may help guide the ELNT in their continuous endeavor to improve English language curricula for initial stages in the kingdom. 


\section{METHODOLOGY}

\subsection{Subjects}

Sixty second-grade female children from Um Huthayfah Primary School for Girls, a state school in Abu Noseir area in the north of Amman, served as the subjects of the study (Average age $=7.1$ ). According to their classroom teachers, all participants were progressing normally in speech, language, and learning development. The subjects' native language is Arabic, and as is the case in all Jordanian state schools, English has been taught to them as a foreign language using Action Pack series since the beginning of 2006-7 academic year. Besides, almost all the subjects have had the chance to learn some English in kindergartens: families in this area are generally educatedmiddle class; and thus keen on children's preschool education. As such, the children were expected to show clearer responses to PA instruction. The English language teachers at this school had shown exceptional cooperation and eagerness to participate in running the scheduled PA sessions and in administering the required PA tests (see below), and this was probably the main reason for selecting this school. However, the results obtained can be generalizable given that the curricula adopted for second-graders are the same in all Jordanian state schools, in addition to apparent resemblance in teachers' qualifications, schools' facilities, and parents' socio-economic status.

\subsection{Phonological Awareness Pre-and Post-test}

A month before the end of the first semester of the 2007-2008 school year, the subjects randomly assigned to a control group $(\mathrm{N}=30)$; and to an experimental group $(\mathrm{N}=30)$ were asked to sit for a PA pre-test: Robertson and Salter's (1997) Phonological Awareness Test (PAT). As a standardized PA test, PAT measures children's ability to perform a number of PA activities assumed to build their general PA aptitudes. Though the PAT consists of eight sub-tests examining eight respective skills, only five sub-tests were adopted, for relevance, in the present study: segmentation, isolation, deletion, substitution and blending. Sub-tests on rhyming, graphemes and decoding were excluded as the former is a kindergarten skill (see the subjects' relatively high rhyming score in table 1 above), and the latter two seem to be more relevant to research on reading development, a topic out of the scope of this study. Pursuant to PAT, the pre-test was held in a quiet classroom in the subjects' school. A one-by-one testing was adopted, and carried out by a team of English language tutors $(\mathrm{N}=6)$ (see below).

The specifics of the PA skills and their constituent sub-skills examined in the PAT pre-test were as follows. Segmentation includes three sub-skills: segmenting sentences into words; words into syllables; and syllables into phonemes. Likewise, isolation comprises three: isolating initial; final; and 
medial sounds. Deletion consists of two: deleting compounds and syllables; and deleting phonemes. Substitution is just one skill: manipulating sounds, and so is blending which only includes blending syllables and phonemes. Ten testing items were allocated to each sub-skill. The total score for each PA skill is the combination of its different sub-skills scores. For instance, the individual sub-scores given for segmenting sentences into words; words into syllables; and syllables into phonemes make the total score for the segmentation skill. If the child missed more than 5 items in a row in one part, the test was discontinued.

The PAT pre-test results showed that there were no significant differences between the experimental and the control group $(\mathrm{P}=.923)$ (see table 2 below). Thus, any later differences in the mean scores of both groups expected to be found in the PAT post-test results can be unequivocally attributed to PA interventions. Only a week after the PAT pre-test was held, the experimental group joined a three-week PA training program focusing on the five phonological skills in question, whereas the control group continued to receive formal classroom instruction based on Action Pack 2 . Shortly after the end of the program, both groups were asked to sit for the PAT post-test, which was actually the same PAT pre-test, held again under the same examination conditions.

\subsection{Phonological Awareness Training Program}

The PA instruction material, prepared by the researcher, presumed that certain PA skills are easier while others are more challenging. According to Yopp (1988), identifying phonemes, for instance, is easier than manipulating phonemes, and producing phonemes is more difficult than either manipulating or identifying them. Following Adams (1990), Yopp (1992), Stanovich (1994), and Chard and Dickson (1999), the PA instruction material designed consisted of five PA skills presented in increasing difficulty: segmentation, isolation, deletion, substitution and blending. The reason for integrating material on these particular skills is their reported impact on increasing children's PA (e.g. Robertson and Salter, 1997).

To maximize the validity of the PA training material, it was given to a jury of judges: two Professors of Phonology; two EFL supervisors; and other two EFL teachers. The jury was requested to evaluate this material and the different PA tasks required. Feedback and recommendations were taken into account in rewriting the tasks. Following is a brief account of the material used and the tasks involved in this program.

\subsubsection{Segmentation}

Children were taught that segmentation is breaking speech down into its individual constituents, and familiarized with three related sub-skills: sentence 
segmentation (breaking sentences into individual words), word segmentation (breading words into individual syllables), and syllable segmentation (breaking syllables into individual phonemes). Thus, three phonological tasks were required:

a. Sentence Segmentation: students were asked to clap the different words in sentences as a gesture of correct segmentation. Examples:

He can swim (3 claps)

My cat is black (4 claps).

b. Syllable Segmentation: students were asked to clap the different syllables in words. Examples:

If I say, 'sunshine', you say /sun/, /shine/.

If I say 'hospital', you say /hos/, /pi/, /tal/).

c. Phoneme segmentation: students were asked to tell the sounds they hear in words by stressing every sound. Examples:

If I say 'hot', you say $/ \mathrm{h} /, / \mathrm{o} /, \mathrm{t} / \mathrm{t}$.

If I say 'car', you say $/ \mathrm{k} /, / \mathrm{a} /, \mathrm{r} /$

\subsubsection{Phoneme isolation}

Students were taught the concept of phoneme in its broad sense (i.e. individual functional sounds), and shown how to identify/ isolate phonemes in different in-word positions: initial, final, and medial. Three phoneme isolation tasks were involved:

a. Initial isolation: students were asked to isolate initial phonemes (e.g. what sound does the word "hot" start with?)

b. Final isolation: students were asked to isolate final phonemes (e.g. what sound do you hear at the end of "bus"?)

c. Medial isolation: students were asked to isolate phonemes in the middle of words (e.g. what sound do you hear in the middle of "cap"?)

\subsubsection{Deletion}

Students were instructed on manipulating root words, and syllables and phonemes in words. Two tasks were involved:

a. Compounds and Syllables: students were asked to delete one root word or syllable (e.g. Say 'rainbow' without 'rain', Say 'cupcake' without 'cake'). 
b. Phoneme deletion: students say a word and then say it again, deleting one of its phonemes. Examples:

Say 'band' without 'b' (and)

Say 'link' without 'l' (ink)

Say 'heat' without ' $h$ ' (eat)

\subsubsection{Substitution:}

Students were taught sounds manipulation skill. One task is involved: changing a sound in a word in order to make new words. Examples:

What word do you make when you change the /b/ in 'bag' to /t/? (tag)

What word do you make when you change the $/ \mathrm{s} /$ in 'sun' to $/ \mathrm{r} /$ ? (run)

\subsubsection{Blending:}

Students were taught and asked to blend sounds to make words. Examples:

$-/ \mathrm{m} / / \mathrm{o} / / \mathrm{p} /(\mathrm{mop})$

$-/ \mathrm{b} / / \mathrm{a} / / \mathrm{t} /(\mathrm{bat})$

$-/ \mathrm{b} / / \mathrm{e} / \mathrm{e} /(\mathrm{bee})$

Using this material, the experimental group underwent fifteen 40-minute PA sessions; three for each skill. As stated earlier, the instruction program was conducted over 3-week period; students received an average of 600 minutes of small-group instruction, as it was found to be the most effective format for PA interventions (e.g. Pullen, 2002). Thus, the experimental group $(\mathrm{N}=30)$ was divided into six subgroups; five in each. In order to make PA activities interesting and meaningful, words and sentences were illustrated by color pictures which were labeled with their English names or the sentences that describe them. Corrective feedback was given during the instruction sessions. In all PA tasks, feedback modeling of successful answers was also provided so that children can understand the tasks.

By permission from the school administration, the program was carried out by a team of six female tutors, including four English language instructors from the Language Center of the Hashemite University, and other two experienced English language teachers from Um Huthayfah Primary School for Girls. Before commencement, the tutors themselves had already received the researchers' orientation regarding running the program. The progress of the sessions was monitored by the researcher through his subsequent visits to the school during the program period, and via the tutors' feedback. Owing to the teachers' friendliness, the children enjoyed learning the PA skills. 


\section{RESULTS AND DISCUSSION}

In this section, the effectiveness of explicit PA interventions (in contrast with formal classroom instruction) on developing the subjects' PA is discussed. The section consists of two parts; the first is a macroscopic view of the overall experimental and control groups' PAT pre- and post- test results, while the second is a microscopic one that compares and contrasts the specific details of these results.

\subsection{Macroscopic view}

As expected from homogeneous second-grade classes whose children have had the same EFL experience, the overall PA pre-test results on PAT assessment measures show no statistically significant differences between both experimental and control group $(\mathrm{P}=.923)$, as exhibited in table (2) below.

Table 2: Overall experimental and control groups' PA pre-test results on PAT assessment measures

\begin{tabular}{|l|l|l|l|l|l|}
\hline GROUP & $\mathbf{N}$ & Mean & Standard Deviation & T & P \\
\hline Experimental & 30 & 191.00 & 55.74 & .097 & .923 \\
\cline { 1 - 3 } Control & 30 & 189.63 & 54.41 & & \\
\hline
\end{tabular}

Given this sameness, and the experimental group's PA sessions, one may only conclude that any subsequent statistical differences between both groups can be attributed to the impact of these sessions.

Unsurprisingly, the overall PA post-test scores obtained for both groups on the same PAT pre-test measures demonstrate significant differences, as shown in table (3) below.

Table 3: Overall experimental and control groups' post-test results on PAT assessment measures

\begin{tabular}{|l|l|l|l|l|l|}
\hline GROUP & N & Mean & Std. Deviation & T & P \\
\hline Experimental & 30 & 239.22 & 60.85 & 2.39 & $.020^{*}$ \\
\cline { 1 - 3 } Control & 30 & 203.63 & 54.90 & & \\
\hline
\end{tabular}

* Significant

Obviously, the children in the experimental group have significantly outperformed their peers in the control group $(\mathrm{t}=2.39, \mathrm{P}=.020)$ in the overall PA post-test, suggesting that explicit PA intervention was considerably more 
beneficial and more effective in building PA skills than formal classroom instruction based in the case of those graders on Action Pack 2.

The great PA gain the experimental group has received from the PA training program becomes more transparent when its own PA pre-and post test results are compared, as demonstrated in table (4) below.

Table 4: Overall experimental group's pre-and post-test results on PAT assessment measures.

\begin{tabular}{|l|l|l|l|l|l|}
\hline Test & N & Mean & Std. Deviation & T & P \\
\hline Pre-test & 30 & 191.00 & 55.74 & -3.59 & $.001^{*}$ \\
\cline { 1 - 4 } & 30 & 244.22 & 60.85 & & \\
\hline
\end{tabular}

* Significant

The table shows the experimental group's noticeable advancement in PA skills $(\mathrm{t}=-3.59, \mathrm{P}=.001)$. The significant differences between the group's performance in both pre-and post-test are unequivocally attributed to the group's PA interventions.

On the contrary, the control group's PA pre- and post-test results have shown similar mean scores and standard deviations, pointing to no significant differences in its children's advancement $(\mathrm{t}=-1.63, \mathrm{P}=.109)$, as illustrated in table 5 below.

Table 5: Overall control group's PA pre-and post-test results on PAT assessment measures

\begin{tabular}{|l|l|l|l|l|l|}
\hline Test & $\mathbf{N}$ & Mean & Std. Deviation & $\mathbf{T}$ & $\mathbf{P}$ \\
\hline Pre-test & 30 & 189.63 & 54.41 & -1.630 & .109 \\
\cline { 1 - 4 } Post-test & 30 & 212.63 & 54.90 & & \\
\hline
\end{tabular}

It is clear from table 5 that formal classroom instruction did not seem to have any positive impact on improving the control group's PA, and this is probably the root of the phonological problems Jordanian EFL learners develop over the years (see section II above). Children who fall behind at an early grade fall further and further behind over time. Thus, the protocol seems to be: poor early stages' PA; impoverished later stages' pronunciation, and the reverse is also true.

In brief, the overall results demonstrated in tables (2-5) above provide empirical evidence supporting the research hypothesis that explicit PA intervention is more effective for building Jordanian EFL second-graders' PA than formal classroom instruction. The results seem to confirm Tamimi and Rababah's (2007) finding of some initial indications of the usefulness of PA 
training for Jordanian EFL first-graders in governmental schools. They also seem to be consistent with Layton et al.'s (1998: 38) finding that "the effects of weak or under-developed awareness can be reduced by intensive training". The microscopic view presented below provides more solid grounds for corroborating previous research conclusions.

\subsection{Microscopic View}

Having proved, based on overall PA pre-and post- test results, that PA explicit training is more effective in developing the subjects' PA than formal classroom instruction, it is deemed necessary to tackle in some detail the impact of PA training on each of the five PA skills in question for both groups.

\subsubsection{Segmentation and Isolation}

It has to be remembered that segmentation test is a composite of three sub-tests, including the child's ability to segment sentences into words; words into syllables; and syllables into phonemes. Likewise, isolation test is a structure of three sub-tests related to the child's ability to isolate phonemes in initial, final, and medial positions.

The paired sample analysis demonstrated in table 6 below shows no significant differences between the mean scores of the experimental and the control groups in both segmentation and isolation as assessed in both pre- and post-tests (PAT). It also reveals no significant differences for the experimental group itself in both skills; for segmentation, the mean scores were 64.45 in the pre-test and 65.77 in the post-test; and for isolation, they were 54.00 and 56.45 , respectively.

However, the numeric values may indicate a little more improvement in the experimental group's performances in both skills. While the post-test mean score for the control group in segmentation was 64.40, it was 65.77 for the experimental group; while it was 54.73 in isolation for the former group, it was 65.45 for the latter. For the experimental group, there is also a slightly better progress: whereas its pre-test mean score in segmentation was 64.45 , it mildly increased to 65.77 in the pos-test, and while the pre-test mean score in isolation was 45.00 , it slightly moved to 65.45 in the post-test. Though this numeric contrast may provide little support to PA instruction on these skills, what counts after all is the statistical interpretation that suggests no significant differences.

However, there is no wonder to find similar results for second-graders in both groups on measures of segmentation and isolation because these aptitudes are presumed to be less challenging than the other PA ones (i.e. deletion, substitution and blending). As such, the results may lend some support to the views ranking PA skills on a continuum from the easier to the 
more difficult (Yopp 1988; Adams, 1990; Stanovich, 1994; Chard and Dickson, 1999). Also, the impact of PA training on developing segmentation and isolation in contrast with formal classroom instruction cannot be undermined in view of the present results for two main reasons. First, the subjects' previous exposure to English as kindergartners and first-graders might have stimulated some awareness of these skills. Jordanian EFL firstgraders, for instance, are expected by the end of the year "to pronounce the letters of the alphabet, pronounce simple words accurately (e.g. numbers 110), imitate the pronunciation of some simple English words, and pronounce after listening to a tape" (ELNT, 2006: 16). Second, PA experiments on kindergartners and first-graders have already shown the effectiveness of PA interventions in developing these particular skills (e.g. Blachman, 1991; Robertson and Salter, 1997). Anyway, the relevance of PA remediation can be better seen for the subjects in more challenging PA skills: deletion, substitution, and blending, as discussed below.

Table 6: Experimental and Control groups' PA pre-post-test scores for segmentation and isolation

\begin{tabular}{|l|l|l|l|l|l|l|}
\hline Test & GROUP & $\mathbf{N}$ & Mean & $\begin{array}{l}\text { Std. } \\
\text { Deviation }\end{array}$ & T & P \\
\hline \multirow{2}{*}{$\begin{array}{l}\text { Segmentation } \\
\text { (Pre-test) }\end{array}$} & Experimental & 30 & 64.45 & 14.91 & .092 & .927 \\
\cline { 2 - 6 } & Control & 30 & 64.10 & 14.86 & & \\
\hline $\begin{array}{l}\text { Segmentation } \\
\text { (Post-test) }\end{array}$ & Experimental & 30 & 65.77 & 14.71 & .360 & .720 \\
\cline { 2 - 5 } & Control & 30 & 64.40 & 15.08 & & \\
\hline \multirow{2}{*}{ Isolation (Pre-test) } & Experimental & 30 & 54.00 & 15.50 & -.164 & .870 \\
\cline { 2 - 5 } & Control & 30 & 54.63 & 14.59 & & \\
\hline \multirow{2}{*}{$\begin{array}{l}\text { Isolation (Post- } \\
\text { test) }\end{array}$} & Experimental & 30 & 56.45 & 15.27 & .452 & .653 \\
\cline { 2 - 5 } & Control & 30 & 54.73 & 14.41 & & \\
\hline
\end{tabular}

\subsubsection{Deletion}

Deletion on PA continuums is considered more challenging than both segmentation and isolation. Its test, as stated earlier, involves two main subtests: the ability to obliterate one root word or syllable; and phonemes in words. The Experimental and the control groups' PAT pre-and post- test results for deletion are presented in table 7 below.

The paired sample analysis demonstrated in table 7 shows significant differences between the mean scores of both groups in deletion subt-ests $(\mathrm{t}=$ $4.25, \mathrm{P}=.000$ ), thus providing evidence in favor of the effectiveness of explicit PA instruction in building this skill. Conversely, the results reveal formal classroom instruction to be less effective. It may be concluded that as PA skills get more challenging to children, preference should be given to the 
VOLUME 9

former strategy rather than the latter. Results on substitution and blending confirm this conclusion.

Table 7: Experimental and control groups' PAT pre-post-test scores for deletion

\begin{tabular}{|l|l|l|l|l|l|l|}
\hline Test & GROUP & $\mathbf{N}$ & Mean & $\begin{array}{l}\text { Std. } \\
\text { Deviation }\end{array}$ & $\mathbf{T}$ & $\mathbf{P}$ \\
\hline \multirow{3}{*}{ Pretest } & Experimental & 30 & 30.51 & 10.65 & .198 & .844 \\
\cline { 2 - 5 } & Control & 30 & 30.00 & 9.71 & & \\
\hline \multirow{2}{*}{ Posttest } & Experimental & 30 & 55.48 & 12.07 & 4.254 & $.000^{*}$ \\
\cline { 2 - 5 } & Control & 30 & 43.23 & 10.31 & & \\
\hline
\end{tabular}

\subsubsection{Substitution}

Substitution is regarded as more challenging than the previous three skills on PA hierarchies, as it is a manipulation skill. It has to be remembered that PAT examines it as one skill involving the subjects' ability to change sounds in words in order to make new words. Here again, the experimental group outperforms the control group on measures of this skill, as shown in table 8 below.

Table 8: Experimental and control groups' PAT pre-post-test scores for substitution

\begin{tabular}{|l|c|c|c|c|c|c|}
\hline Test & GROUP & $\mathbf{N}$ & Mean & Std. Deviation & $\mathbf{T}$ & $\mathbf{P}$ \\
\hline \multirow{3}{*}{ Pre-test } & Experimental & 30 & 24.38 & 9.36 & .260 & .796 \\
\cline { 2 - 7 } & Control & 30 & 23.76 & 9.26 & & \\
\hline \multirow{3}{*}{ Post-test } & Experimental & 30 & 29.64 & 10.90 & 2.39 & $.020^{*}$ \\
\cline { 2 - 5 } & Control & 30 & 21.06 & 9.42 & & \\
\hline
\end{tabular}

The paired sample analysis in table 8 demonstrates significant differences between the mean scores of the experimental and control group in substitution $(\mathrm{t}=2.39, \mathrm{P}=.020)$. One can immediately conclude that PA training is more effective in developing this essential skill than formal classroom instruction.

\subsubsection{Blending}

Blending is presumably the most difficult skill on PA continuums, especially since its test examines the children's ability to blend sounds in order to make words. As expected, the experimental group's performance in this also one-skill-test was much better than that of the control group, as illustrated in table 9 below.

The paired sample analysis presented in table 9 above shows that there were significant differences between the mean scores of the experimental and 
control groups in blending $(\mathrm{t}=4.90, \mathrm{P}=.000)$, suggesting once again that PA remediation is more beneficial for developing this vital PA skill than formal classroom instruction.

Table 9: Experimental and control groups' PAT pre-post-test scores for blending

\begin{tabular}{|l|l|l|l|l|l|l|}
\hline Test & GROUP & N & Mean & Std. Deviation & T & P \\
\hline Pre-test & Experimental & 30 & 17.64 & 7.03 & .267 & \\
\cline { 2 - 6 } & Control & 30 & 17.13 & 7.90 & & .790 \\
\hline Post-test & Experimental & 30 & 31.87 & 9.43 & 4.90 & \\
\cline { 2 - 5 } & Control & 30 & 20.20 & 7.85 & & $.000^{*}$ \\
\hline
\end{tabular}

It is obvious from the foregoing discussion based on tables (6-9) that the Jordanian EFL second-graders who underwent PA training sessions have excelled in at least three more challenging PA skills; namely, deletion, substitution and blending. Their performance in the other two skills (i.e. segmentation and isolation) was also slightly better (though statistically insignificant) than that of their peers in the control group who continued to receive regular English language classes. The research hypothesis that PA training is more effective in PA building than formal classroom instruction is thus supported. Thus, the research findings corroborate previous research conclusions to the same effect (Lundberg, Olofsson, and Wall, 1980; Foorman et al., 1991; Stuart, 1995; Bus and Van Ijzendoorn, 1999; Torgesen, 2000; Chera, 2000; Ehri et al., 2001; Vaughn et al., 2001; Gunn et al., 2002; Chera and Wood, 2003; Wood, 2005; Littleton, Wood and Chera, 2006; Tamimi and Rababah, 2007).

The results also lend some support to the view that for EFL as well for monolingual students, PA interventions can be an effective strategy (e.g. Snow, Burns, and Griffin, 1998; Layton, 1998; Leafstedt, Richards, and Gerber, 2004).

The experimental group in the present research is probably the virtual second-graders' model that can more comfortably meet the requirements of the Jordanian English Language National Team (2006). Presumably, by virtue of their more established core cognitive aptitude (cf. Cisero and Royer, 1995; Richards, 2004), or their more developed metalinguistic ability, they are more able "to speak English clearly and correctly in the context of basic and simple guided short exchanges and presentations" (ELNT, 2006: 20), and more empowered to "pronounce two-syllable words with the correct stress, pronounce words correctly when talking about animals, clothes, presents and members of the family, ask and respond to short simple questions about clothes and colors using short sentences..." (ibid). 


\section{CONCLUSION}

Based on the evidence cited above, it seems safe to state that addressing the needs of low performers in phonology requires integrating a number of phonological awareness activities related to segmentation, isolation, deletion, substitution and blending in Jordanian primary schools' curricula, starting with basic stages. This integration is expected to lessen EFL learners' pronunciation problems in subsequent academic stages.

\section{REFERENCES}

Abed Al-Haq F.(1997). Production of English sentence stress by Yarmouk University majors. Journal of the College of Teachers. 9, 1, 1-21

Adams M. \& Henry M. (1997). Myths and realities about words and literacy. Schools Psychology Review, 26, 3, 425-436.

Adams M. (1990). Beginning to read: thinking and learning about print. Cambridge: MIT Press

Anani M. (1989). Incorrect stress placement in the case of Arab [Jordanian] learners of English. IRAL, International Review of Applied Linguistics in Language Teaching, 27, 1, 15-21

Anthony L. \& Francis D. (2005). Development of Phonological Awareness. American Psychological Society, 14, 5, 255-258.

Aziz Y. (1974a). Some problems of English consonant sounds for the Iraqi learner. English Language Teaching Journal, 28, 2, 66-168.

Aziz Y. (1974b). Some problems of the English diphthongs for the Iraqi learner". English Language Teaching Journal, 29, 1, 68-71.

Aziz, Y.(1980). Some problems of English word-stress for the Iraqi learner. English Language Teaching Journal, 34, 2, 104 -109

Ball E. \& Blachman B. (1991). Does phoneme awareness training in kindergarten make a difference in early word recognition and developmental spelling?' Reading Research Quarterly, 26, 49-66.

Blachman B. (1991). Early intervention for children's reading problems: clinical applications of the research in phonological awareness". Topics in Language Disorders, 12, 51-65

Brady S, Fowler A., Stone B. \& Winbar N. (1994) Training phonological awareness: a study with inner-city kindergarten children. Analysis of Dyslexia, 44, 27-59

Bus A. \& Van Ijzendoorn M. (1999). PA and early reading: a meta-analysis of experimental training studies". Journal of Educational Psychology, 91, 3, 403414

Catts H., Fey M., Zhang X., Tomblin, \& Bruce, J. (2001). Estimating the risk of future reading difficulties in kindergarten Children: a research-based model and its clinical implementation. Language, Speech, and Hearing in Schools, 32, 1, 38-50.

Chard D. \& Dickson S. (1999). Phonological awareness: instructional and assessment guidelines. LD online, Retrieved on March 6, 2012 from www.ldonline.org/article/6254 
Chera, P. \& Wood C. (2003). Animated multimedia 'talking books' can promote phonological awareness in children beginning to read". Learning and Instruction, $13,33-52$

Chera P. (2000). Multimedia CAL and early reading: iterative design, development and evaluation. Unpublished $\mathrm{PhD}$ dissertation, University of Bristol.

Cisero C. \& Royer J. (1995). The development and cross-language transfer of PA. Contemporary Educational Psychology, 20, 275-303

Cunningham, A. (1990). A developmental study of instruction in phonemic awareness". Paper presented at the meeting of the American Educational Research Association, New Orleans.

Ehri L., Nunes S., Willows D., Schuster B., Yaghoub-Zadeh, Z., \& Shanahan, T. (2001). Phonemic awareness instruction helps children learn to read: Evidence from the national Reading Panel's meta-analysis. Reading Research Quarterly, $36,3,250-287$.

Fender M. (2003). English word recognition and word integration skills of native Arabic and Japanese- speaking learners of English as a second language. Applied Psycholinguistics, 2, 289-315.

Foorman B. \& Liberman D. (1989). Visual and phonological processing of words: a comparison of good and poor readers. Journal of Learning Disabilities, 22, 6, 349-355.

Foorman, B., Francis, D., Novy, D. \& Liberman, D. (1991). How sound-letter instruction mediates progress in first-grade reading and spelling. Journal of Educational Psychology, 83, 4, 456-469

Gillet J., Temple C. \& Crawford A. (2004). Understanding reading problems: assessment and instruction. Boston: Allyn and Bacon.

Gunn B., Smolkowskil K., Biglan A., \& Black C. (2002). Supplemental instruction in decoding skills for Hispanic and non-Hispanic students in early elementary school: A follow-up. Journal of Special Education, 36, 69-79

Hancock P. (2006). Action Pack 2 second grade. London: York Press

Khalil H. (1987). Problems of Perception and Production of English Intonation by Egyptian Learners and Teachers of English. $\mathrm{PhD}$ dissertation, Alexandria University, Egypt

Kharma N. (1981). Analysis of the errors committed by Arab university students in the use of the English definite/indefinite articles". IRAL, International Review of Applied Linguistics in Language Teaching, 19, 4, 333-345.

Layton L., Deeny K, Upton G. \& Tall G. (1998). A pre-school training program for children with poor phonological awareness: effects on reading and spelling. Journal of Research in Reading, 21, 1, 36-52.

Leafstedt J., Richards C., \& Gerber M. (2004) Effectiveness of explicit phonologicalawareness instruction for at-risk English learners". Learning Disabilities Research and Practice, 19, 4, 252-261

Littleton K., Wood C. \& Chera P. (2006). Interaction with talking books: phonological awareness affects boys' use of talking books. Journal of Computer Assisted Learning, 22, 382-390.

Lundberg I., Olofsson A., \& Wall S. (1980). Reading and spelling skills in the first school years, predicted from phonemic awareness skills in kindergarten". Scandinavian Journal of Psychology, 21, 159-173. 
Lundberg I., Frost J., \& Petersen, O. (1988). Effects of an extensive program for stimulating phonological awareness in preschool children. Reading Research Quarterly, 23, 3, 263-284.

Mattar H. (1990). A cross-sectional error analysis study of the common writing errors made by adult Arabic-speaking EFL learners in Bahrain. $\mathrm{PhD}$ dissertation, University of East Anglia, UK.

Mukattash L. (1983). The Problem with difficulty in foreign language learning. In Dahiyat, E. \& Ibrahim, M. (eds.) Papers from the First Conference on the Problems of English Language and Literature at Arab Universities, University of Jordan, 145-175.

Pullen P. (2002, October 1). "Expert connection: Phonological awareness". Teaching LD. Org. Retrieved Feb. 6, 2012 from:

http://TeachingLD.org/expert_connection/phonological.html

Rabab'ah Gh. (2005). Communication Problems Facing Arab Learners of English. Journal of Language and Learning, 1, 3, 180-197.

Richards C. (2004). Response to instruction: a study of phonological awareness instruction for kindergartner English learners. Unpublished $\mathrm{PhD}$ dissertation, University of California, Santa Barbara.

Robertson C. \& Salter W. (1997). The phonological awareness test. East Moline, IL: LinguiSystems, Inc.

Ryan A. \& Meara P. (1991). The case of the invisible vowels: Arabic speakers reading English words. Reading in a Foreign Language, 7, 531-540.

Snow C., Burns M. \& Griffin P. (eds.). (1998). Preventing reading difficulties in young children. Washington, DC: National Academy Press.

Stanovich K. (1994). Does dyslexia exist?. Journal of Child Psychology and Psychiatry, 35, 579-595.

Stuart M. (1995) Prediction and qualitative assessment of five-and six-year-old children's reading: a longitudinal study. British Journal of Educational Psychology, 65, 287-296

Suter R. W. (1976). Predictors of pronunciation accuracy in second language learning. Language Learning, a Journal of Applied Linguistics, 26, 2, 233-253.

Tamimi Y and Rababa G., (2007). The relationship between phonological awareness and word reading. Poznan Studies in Contemporary Linguistics-PSiCL, 43, 2, 5 21

The English Language National Team, Ministry of Education, Jordan (2006). General guidelines and general and specific outcomes for the English language: basic and secondary stages, Eepc: Amman, Jordan

Torgesen J. (2000). Individual differences in response to early interventions in reading: the lingering problem of treatment resisters. Learning Disabilities Research and practice, 15, 1, 55-64

Vaughn S., Hughes M., Moody S. \& Elbaum B. (2001). Instructional grouping for reading for students with learning disabilities: implications for practice. Intervention in School and Clinic, 35, 131-137.

Wanger R. \& Torgesen, J. (1987). The nature of phonological processing and its causal role in the acquisition of reading skills. Psychological Bulletin, 101, 2, 192-212. 


\section{RELEVANCE OF PHONOLOGICAL AWARENESS}

Wanzek J, Dickson S, Bursuck W \& White J. (2000). Teaching phonological awareness to students at risk for reading failure: an analysis of four instructional programs. Learning Disabilities: Research and Practice, 15, 4, 226-39.

Wood C. (2005). Beginning readers' use of 'talking books' software can affect their reading strategies. Journal of Research in Reading, 28, 170-182

Yopp H. (1988). The validity and reliability of phonemic awareness tests. Reading Research Quarterly, 23, 159-177.

Yopp H. (1992). Developing phonemic awareness in young children. The Reading Teacher, 45, 9, 696-703 